\title{
In Conversation with Fikile Nxumalo: Refiguring Onto-Epistemic Attunements for Im/possible Science Pedagogies
}

\author{
Fikile Nxumalo and Maria F.G. Wallace
}

Maria Wallace: One of the big threads that we were talking about that we wanted to hear your perspective on is related to the complicated context of science. So in science as both a discipline of knowledge, but also a context of study and so forth. There are so many problematic kinds of assumptions that get kind of taken up in that, whether it's independent, historical, or ontological considerations of how we might romanticize our understanding of what constitutes nature, as well as destructive or hegemonic socio-ecological relationships. So, I know that a lot of your work deals with children, but also, just thinking about how we inherit these dialogues or narratives of nature and culture come through. If you could talk a little bit about the nature-culture divide either from whatever perspective you want or if you think about children as a particular starting point.

Fikile Nxumalo: Yes. My engagement with the idea of inheritances and their unevenness is about trying to bring to the context of early childhood education critiques of the universalizing effects of discourses of the Anthropocene as the so-called age of Man, where humans are the primary drivers of planetary changes. There have been several critiques of the Anthropocene from

F. Nxumalo $(\varangle)$

University of Toronto, Toronto, ON, Canada

e-mail: f.nxumalo@u.toronto.ca

M. F.G. Wallace

Center for Science and Mathematics Education, University of Southern Mississippi, Hattiesburg, MS, USA

e-mail: maria.wallace@usm.edu 
many different perspectives, including feminist geographies, Black studies, and Indigenous studies that have pointed out that dominant discourses of the Anthropocene don't bring sufficient attention to the ways in which marginalized populations are not only differently responsible for anthropogenic damage; they're also disproportionately vulnerable. So my ethical commitments in my work include centering the ways in which early education, including science education, can resist and subvert rather than reinscribe the universalisms and erasures of the Anthropocene. This includes asking how early childhood pedagogy might include attention to the specific geographies of children's inheritances of environmental precarity.

This attention to uneven inheritances is also part of my thinking on possibilities for unsettling nature/culture divides in early childhood education. So asking, for example, when it is said that children are needing reconnection with nature, which children are we talking about? What assumptions of childhood underpin pedagogies of reconnecting to nature? What is meant by nature-this is an important question to ask in relation to current environmentally damaged places that children are unevenly inheriting. What is left out about the morethan-human connections that are always already there? This is not to suggest that there are universal "right" answers to these questions but rather to think about how place-based pedagogies might disrupt colonial and universalizing assumptions about nature and children or childhoods. Megan Bang and Affrica Taylor are two people whose work has been particularly inspirational for me thinking about these questions and their pedagogical and curricular implications in the actual places and spaces in which I work with young people and educators.

Maria: Yeah. And as you were talking, I was starting to think about how you were pointing out a couple of different kinds of inheritances. So there's the human dimension, but also the nonhuman inheritance, whether that's the physical material or the ideological. And so maybe if you could expand a little bit on that, the ways in which there's this intergenerational, whether it's human or nonhuman, exchange of our conceptions of what constitutes nature or even culture and how that's taken up personally in different bodies, geographical contexts, and so forth. So there are these different, multifaceted ways in which we can think about the inheritance of science or nature or ways of knowing and being, I think. And so some of what I heard you talking about too is that that gets mapped onto human bodies in particular ways, but also the nonhuman dimension. So like the ideas about nature and how human bodies carry those through wherever they're at. But also then the inheritance of the land or the water and how stories get kind of brought into that assemblage.

Fikile: Yes. I also want to add that part of this work with educators is unpacking our assumptions about nature, and children's relations with nature and how they may influence what we do with children and what we pay attention to as we engage in place-based learning. So with regards to inheritances I would say they show up in the everyday in different ways. For example, I have written about the discourse of discovery as it relates to the ways in which children's encounters with nature might be narrated. So one could think of discovery as something that might seem somewhat benign but can actually be a reproduction of colonial inheritances of nature as something separate from humans, awaiting children's meaning-making rather than, for instance, considering how 
nature is always already pedagogical, agentic, and in-relation with humans in different ways.

Something else in relation to inheritance is that for me it is important to attend to the ways in which inheritance is fraught, political, and filled with inequities. A lot of my work has been in contexts where the children are for the most part middle-class, white settler children and I think in these settings it is easy to ignore these political aspects of inheritance. So I have found it important to be curious about which inheritances are easily covered over and might need to made visible in our pedagogies. Most often for me this has meant thinking through and finding ways to unsettle the colonial and anti-Black erasures in which our pedagogies are implicated.

Maria: I think that's very helpful and an important point. Especially, thinking about the role of the teacher and the educator of exchange, even if it's not within a school, about reproducing the colonial ways in which our ideas about nature get marked or inscribed on the space as we navigate, or who has access to the spaces. So I think some of the work that you've done, when you talk about working with the children, was in Austin, Texas, as part of the camp or there was an organization? Right?

Fikile: Yes, so when I was referring to working with predominantly white settler children this was in the context of my work in preschool settings in British Columbia and more recently in a kindergarten classroom in Austin, Texas. The summer camp work you are referring to is led by Coahuiltecan elders at the Indigenous Cultures Institute in San Marcos, Texas, where I have been privileged to witness and document a place-based summer camp for predominantly Indigenous and Latinx children and youth. So yes, in relation to the question of access, there continues to be a racial and class divide in terms of which children have access to place-based inquiry learning. At the same time, however, the inspiring pedagogies enacted at the summer camp in San Marcos also show what is possible beyond formal schooling spaces.

Maria: And then wrestling with who has access to these different encounters with nature, there's huge dimension to it, but an inheritance problem as well. The last just question was related to how we document children's experiences with nature. And so one of the things that we're really inspired by too in your work is thinking about what it means to research on these types of questions and these experiences, whether that's on or to have a particular idea about science or education or nature or culture. We were wondering about how you find yourself casting this kind of wide methodological and theoretical perspective net to inform your work with children or unsettle the ways in which we study the child or their experience with nature or culture.

Fikile: Well, perhaps I can talk a little about how I came to that. I want to acknowledge one of my mentors, Dr. Veronica Pacini-Ketchabaw, who has helped me to think through the ways in which the complexities of working with young children require shifting the authority of child development to find ways to challenge normative assumptions about children. The challenging and also most generative part of these ongoing shifts has been working through them in everyday encounters with places, children, and educators. In other words, working through what these shifts might look like as more than theoretical or conceptual shifts but as pedagogy that impacts what we do with children, the questions we ask when we are outside with children, the 
stories we bring to children, the ways in which we write about the places we encounter and children's relations with them... and so on. In terms of working with broad perspectives, I don't think I have a singular answer in how that has come about since, for example, part of that has arisen from unsettling moments that emerge in practice, where it becomes evident that the usual learning theories I might turn to are not enough to, for instance, consider how racialization and colonialism come to matter in the everyday places and spaces of my work with children and educators. I think another important factor has been that in my work I am often trying to grapple with the question of how place-attuned education can simultaneously pay attention to issues of human inequity (for instance, anti-Black assumptions of nature education) and also attend to the more-than-human world in ways that unsettle anthropocentrism. In doing this I have found that I need multiple tools. So recently, in writing about an inquiry on water pedagogies, I found that theories of affect, Black, and Indigenous feminist concepts were all necessary to help me attend to how the planned curriculum that we engaged with as well as what emerged spontaneously, together mattered in relation to decolonizing water pedagogies.

Maria: Yeah, definitely. That's very helpful. Just as a more personal note, that's one of the challenges within science too, we find is there. Are these very linear-bounded ways of knowing the scientific experience or encountering what constitutes science? And so really embracing the complexity of all of these kinds of compounding things that get mashed up into a human subject and also beyond the human subject. It requires a much more diverse set of skills to draw on. And your work is really one great example of that.

Fikile: Thank you. I would like to add to the example that I just mentioned in relation to trying out different water pedagogies with the kindergarten children. In this work we have also engaged with Western science, so, for example, doing all kinds of water testing with the children and learning about aspects of the ecologies of the creek where we spent our time together. At the same time, I am always thinking about the limits of Western science as ways of knowing, relating, and becoming with environmentally damaged places. Dr. Megan Bang's work is an important inspiration to me in relation to placebased science learning that is socio-culturally situated and also takes seriously the agency of the more-than-human world. So alongside Western scientific ways of knowing and their affordances, I'm interested in intentional relational practices that have anti-colonial resonances. From my perspective, this anticoloniality can take multiple forms, including the development of an ethic of caring that is less about individual responsibility or stewardship and more about recognizing intrinsic human/more-than-human relationality. I also want to add that joy, play, and playfulness are an important part of this work even as we are working to complicate what Affrica Taylor refers to as the romantic seductive appeal of Nature's child in settler colonial places. Borrowing from Haraway, I am interested in what it might look like to stay with the trouble of learning-with and practicing reciprocity with ecologically damaged landscapes, like the polluted creek we spent time within Austin.

Maria: Right. I think that's a really helpful example because so often folks who end up being drawn to these more critical and complex perspectives want to totally disregard the dominant paradigm. But also what I heard you also 
talking about, which was really interesting, is the way in which as a researcher you draw on these different theoretical and methodological perspectives to come to understand how we research a child's experience or sense making in complicated ways. But the example you also gave that was really helpful was how could we engage children to do that with their encounters with the world as well? So even the pointing out that they engage the testing and the Western science, but also there you're giving them the space in the room to complexify that one account of their water testing with non-Western perspectives at the exact same time.

Fikile: Yes and this work has been immensely enriched by being able to work with Marleen Villaneuva in the first year of the research project. Marleen is a member of the Miakan/Garza Band of Coahuiltecan peoples in Central Texas. She was able to bring to the children situated Indigenous place and water stories. For example, we have written about her sharing with the children a Coahuiltecan creation story that has important lessons about water as human relative, water as agentic, water as life, and more (Nxumalo \& Villanueva, 2020a; Nxumalo \& Villanueva, 2020b). We have then, together with the children and educators, enacted different practices, some planned and some emergent, of being with water in ways that embody and materialize the lessons of this story and other water stories that we have encountered together.

Maria: Right. That's amazing. That sounds like a beautiful practice. We talk about in science ed, the common dominant narrative often is like, bring in a scientist to talk to your class. But again, that then continues to privilege a particular way of knowing science. And so the example you just gave starts to privilege a very different way of knowing nature and culture combined and the complexity of its materializations. So that's really helpful.

Fikile: I also want to acknowledge that this kind of work is difficult within the current structures of many public schooling contexts, particularly as this was a sustained long-term inquiry over the school year, not a "one-time" activity.

Maria: Right. That's a very good point, that it's not just a drop-in moment, but there's a continued relationship between different ways of knowing, being, and communicating with alternative perspectives over an extended period of time.

Fikile: Yes.

Maria: Okay, great. So we've started to talk about it a little bit, but how have children informed your multifaceted perspectives? Whether that's theory or method or your work writ large?

Fikile: Yes. I think this is difficult for me to articulate, because I find it easy for me to slip into the kinds of romantic ways of viewing children and children in nature that I'm wanting to unsettle. I would say the majority of my perspectives have been informed by working with children in particular places and spaces. I am always inspired in observing countless times the ways in which young children can shift their perspectives to attend to the liveliness of the more-than-human world, I think often, though not always, with more of an ease than adults. So in the research that I've been talking about with children and water, myself and the educators tried to be conscious of how we speak of water and engage with water. We found that we also at times slipped into ways of speaking that we were trying to unsettle and at the same times noticing that 
for the children it did not seem as difficult to speak of and with water in ways that noticed its liveliness and agency, including asking for permission, which is one of the teachings that Marleen gifted to the children and educators. So again I am wary of romanticizing and reinforcing a "naturalized" relationship between children and the more-than-human world but also want to emphasize that I learn a lot from children all the time, including their affective, embodied expressive ways of learning-which that can come about when these ways of being are nourished and encouraged to flourish in educational settings.

Maria: Right. That's so cool. You've already started to exemplify this so much in all of your other responses, but you're very helpful and reminding us about the pedagogical encounter-whether it's in a classroom or beyond-and it's dynamic and it's not sometimes intentional and sometimes just always already emerging. And so I'd like to spend some time going more specifically in that direction a little bit of talking at teachers or educators in a broad sense. And so can you discuss a little bit how you enact or invite educators and, however, you conceptualize that to provoke something new or unfamiliar or like you referred to earlier, the unsettling. So how do you invite somebody to start enacting or imagining that in their work?

Fikile: Yes I think I would preface that by saying that I don't have a how to and that this has been possible within the specific contexts where I have worked. In these contexts there have been I think two things that have been vitally important in working with teachers: pedagogical documentation and learning circles (Pacini-Ketchabaw et al., 2014). So, for instance, in the kindergarten classroom, I would spend once a week at the creek with children, teachers, as well as often with Marleen or another graduate research assistant. Pedagogical documentation was a really important way for us to collaboratively and critically reflect on what happened, to ask each other challenging questions, and to collaboratively think together about ways to extend or build on what had emerged the previous week. As part of our documentation for that week I might include a quote for the educators to think with and to collectively push our thinking further about the pedagogy and curriculum that we were trying out. Alongside the pedagogical documentation we also worked with what we called learning circles, where on a regular basis I met with educators to discuss more in depth our documentation alongside readings that I would have shared beforehand to stretch our thinking and bring multiple perspectives to make meaning of children's learning and our pedagogies. I have found these two things together, pedagogical documentation and learning circles, to be really helpful in inviting educators to collaborate in thinking and doing early childhood pedagogies differently. Also not to say that that's necessarily always a comfortable space because it's also about bringing difficult questions about our practices and the taken-for-granted assumptions that inform them-so I am asking for educators to be vulnerable about their practices. For instance, in my book Decolonizing Place in Early Childhood Education I've written about how, particularly when it comes to engaging with issues of settler colonialism, that can be really a difficult, unsettling space.

Maria: That's helpful. And thinking about the unsettling as a productive or generative moment rather than the achieving of the outcome. In educationand I appreciate it that you also mentioned this-we don't have a "how to." 
So often teachers and educators are so interested in the how to, but sometimes the unsettling is the generative exchange or the pedagogical encounter.

So you kind of started to speak at this too, but considering the colonial legacy spread throughout place and practice and ways of knowing the educational experience, can you discuss how you witness or refigure these tensions in your work? And by doing so, or is there anything that is rendered thinkable or actionable for you?

Fikile: I think I would come back to the pedagogical documentation as a starting point; an artifact that materializes, through video, photos, children's and educators' words, our everyday encounters, and then also becomes a site to witness and question what it is that is made visible and what is erased or marginalized-so perhaps the pedagogical documentation helps to make "otherwise" ways of thinking possible. In terms of what is then actionable, that is more difficult. Some questions come up and are taken up, and others less so. I would say though that even those provocations or questions that are not taken easily up directly in practice or perhaps bring some resistance are also still doing something, if that makes sense. That interruptive "doing" can take many forms, some of which is when I'm with children and teachers, and some of which is in returning to those moments by myself. So, for example, I have written about how returning to unsettling moments was inspiration to think with what it might mean to refigure what was actually present in those everyday moments, and for me that meant (re)storying places by foregrounding multiple marginalized stories of particular places.

Maria: There's this tension too in the temporal as a teacher-like the moment when you're with the children or with the students and then the moment after that you come to these different kind of insights to how you might have troubled what we did as a teacher before, or the things related to the colonial impacts of our practice in that moment after the fact. And so the temporal for me and also in the context of the Anthropocene, which is bounded by a different dimensions of time, but feels extra complicated for teachers too and so I appreciate you sharing that. And in the example we see the tension between the moment with and the moment after of having those emerge and be visible either to you or to folks that are in the classroom too.

Much of your scholarship highlights unique partnerships with communities beyond academia, and you've given some of those examples so far in our conversation. So in times like the Anthropocene or Anthropocenes, how do you view your work within or becoming with these multispatial or transdisciplinary contexts, or the partners that you choose to involve or invite, or do they come to you in your work?

Fikile: Thank you. I am really excited by the community-based work I have been involved in, in San Marcos with the elders at the Indigenous Cultures Institute that I mentioned earlier. Importantly for the opportunity to witness and document the important land and climate change education that they are doing. While there are specific teachings that belong to that particular place, I do think there are important lessons on relational, reciprocal, and anti-colonial science that can have broader resonance, including in public school contexts. I should also mention that the work with kindergarten children and teachers in Austin was in an alternative school where there were already openings to 
do place-based pedagogies. So I'm really interested in what might be possible in formal school settings.

Maria: Right. Yeah. I think that's a very helpful reminder because there are so many constraints that get put on public school teachers and formalized school settings that places like a camp or informal space or even walking down the street in some regards have more mobility to work and to de-colonialize particular pedagogies or ways of knowing the world in schools presents a particular kind of challenge for this work. That's beyond many of the settings and where the work is currently happening too.

Do you have any insights into how to navigate that? I work close with teacher education, and I am very attuned to the complexities of the responsibility of a teacher and the tension and the dynamics. And I think many of our potential readers probably will be interested in that as well. And so I'm curious how you imagine navigating that space too with de-colonial pedagogies or decolonizing science in the classroom or nature.

Fikile: Yes. I think that are always possibilities to try something that makes a difference, however, small. So in the Texas school context where I worked, the teachers still had to make connections between what we were doing and the Texas Essential Knowledge and Skills (TEKS). I learned from the teachers in that respect in how they are able to powerfully express our work in connection with and also surpassing those learning requirements. I don't have specific advice in navigating these complexities; I just want to highlight that I learn from teachers with respect to the ways they navigate working within, subverting, and going beyond what the public school system requires with respect to what it means to teach and learn science. The place-based aspect of this of course comes with particular challenges and I again want to emphasize the uniqueness of being able to, as we were, spend an hour outside by a creek each week.

Maria: Right. That's a really good point. And I think an important reminder, especially when we think about working with teachers, that they have the particular skillset when merged in these collaborative ways that can start to render new ideas about decolonizing pedagogy thinkable that weren't maybe before.

So the last question I have is related to the stories and storying and how you find that helpful or in ways that might trigger something different or reconfigure how we move our responsibilities, whether they're temporal or not. How do you see storying and storytelling coming into play for your work or how you conceptualize the nature-culture kind of dichotomy?

Fikile: Yes, I don't think I can emphasize enough how stories are central to everything to me-and this comes from storied teachings I have grown up with in eSwatini as well as what has emerged in my teaching and research in the North American contexts-so yes stories as pedagogy, curriculum, methodology, theory, as ethics and more. I could say a lot about stories and nature/culture divides but perhaps here I would say that old stories are important and at the same time I'm always thinking about ways to tell stories that are not freezing Indigenous people and knowledges to the past. So, for example, asking what are the stories, including science stories, that we can tell that are for Black and Indigenous futures. I wrote an article with my dear friend and colleague kihana ross on thinking with Black speculative fiction storytelling 
and what those might do in imagining what else is possible for Black children's futures outside of current anti-Black formations of schooling, where this also includes resisting deficit constructions of Black children's learning relationships with the more-than-human world (Nxumalo \& Ross, 2019).

Maria: And so I know that when we can talk about or present an alternative story of the future, it renders a new way of being into existence, even in the present moment or the present day. When we talk about futurities in a ways that are unfamiliar or inspiring in regards to the present moment it helps us complexify what it means, the power of time and the conditions in which we move within this moment, whether it's physical or virtual. The stories then allow us to navigate a different plane of being, so it's helpful to hear you talk about the specificity also in that work around Black or indigenous communities and why it's important to render a new image beyond the present moment to escape or to de-colonialize the present moment.

Fikile: Yes and in the article kihana and I are the ones who create the story but I'm really interested in what this could look like working with young people to create situated and anti-colonial speculative science fiction stories, and I am sure there all kinds of examples of this already. One person that comes to mind is Dr. Stephanie Toliver, whose work with Black girls and speculative fiction storytelling is amazing and inspiring.

Maria: And what stories they might tell for themselves that exceed their current moment. Yeah. That's a powerful idea too. I think just the idea that educators might start with stories. So often teachers or educators might bound their pedagogy to a "lock step" lesson plan, but when we just tell a story of a moment, whether it's past or future or non-existent, it produces a new way of coming to know or be.

Fikile: I think you put that really well.

Maria: Now I'm thinking back to the constraints of the classroom experience versus the space that a camp affords or an informal space. And that when or if you invite students to write these speculative futures for themselves, that they might be bound within a school wall or at the institution of a school, but can they write another way of being or beyond that space too?

Fikile: Yes. I think this is really important, particularly in thinking about Black and other historically marginalized children and how to complicate and tell different stories of what it means to belong to certain places, including socalled natural places. So I want to think with what are the possibilities, whether it's through speculative storytelling or through some other pedagogies, about how to interrupt colonial, capitalist, and racialized nature/culture dualisms.

Maria: Right, yeah, that's helpful I think. In science education or nature studies, there's always the leaning and the role of capital. And so I think that's a tension in the desire to capitalize financially, economically, or socially on nonwhite bodies in ways that continue to reproduce the oppressive conditions of the colonial narrative that we might be trying to escape or destabilize or unsettle.

Fikile: Yes. Thank you. 


\section{REFERENCES}

Nxumalo, F., \& Ross, K. M. (2019). Envisioning Black space in environmental education for young children. Race, Ethnicity \& Education, 22(4), 502-524.

Nxumalo, F., \& Villanueva, M. (2019). Decolonial water stories: Affective pedagogies with young children. International Journal of Early Childhood Environmental Education, 7(1), 40-56.

Nxumalo, F., \& Villanueva, M. (2020a). (Re)storying water: Decolonial pedagogies of relational affect with young children. In B. Dernikos, N. Lesko, S. D. McCall, \& A. Niccolini (Eds.), Mapping the affective turn in education: Theory, research, and pedagogy. Routledge (Invited peer reviewed book chapter adapted from article in International Journal of Early Childhood Environmental Education). https://doi. org/10.4324/9781003004219.

Nxumalo, F., \& Villanueva, M. (2020b). Listening to water: Situated dialogues between Black, Indigenous \& Black-Indigenous feminisms. In C. Taylor, J. Ulmer, \& C. Hughes (Eds.), Transdisciplinary feminist research practices: Innovations in theory, method and practice. Routledge (Invited peer reviewed book chapter).

Pacini-Ketchabaw, V., Nxumalo, F., Kocher, L., Elliot, E., \& Sanchez, A. (2014). Journeys: Reconceptualizing early childhood practices through pedagogical narration. University of Toronto Press.

Open Access This chapter is licensed under the terms of the Creative Commons Attribution 4.0 International License (http://creativecommons.org/licenses/by/4.0/), which permits use, sharing, adaptation, distribution and reproduction in any medium or format, as long as you give appropriate credit to the original author(s) and the source, provide a link to the Creative Commons license and indicate if changes were made.

The images or other third party material in this chapter are included in the chapter's Creative Commons license, unless indicated otherwise in a credit line to the material. If material is not included in the chapter's Creative Commons license and your intended use is not permitted by statutory regulation or exceeds the permitted use, you will need to obtain permission directly from the copyright holder.

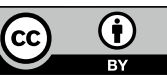

